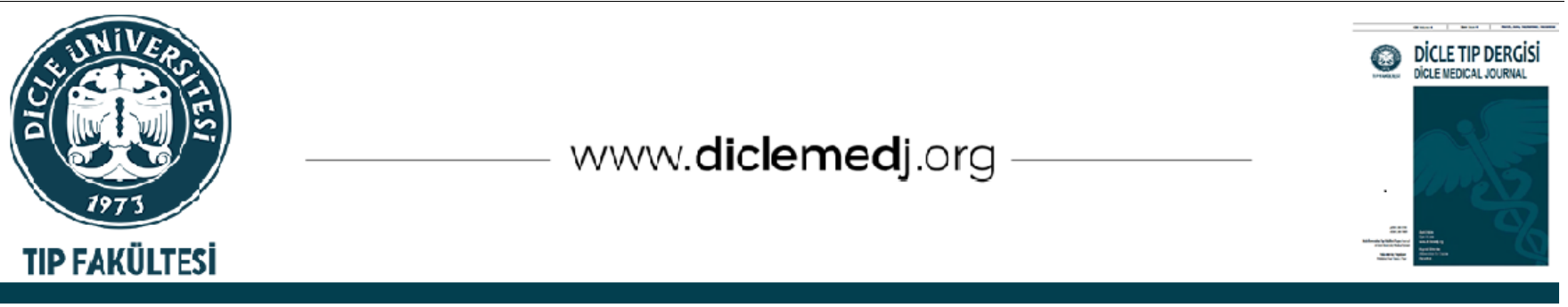

\title{
Karotis Arter Darlı̆ğ ile Birlikte Sınır Zonu İnfarktı Saptanan Olguların Klinik ve Radyolojik Özellikleri ile Karotis Arter Stentlemesinin Erken Dönem Sonuçları
}

\author{
Hasan Hüseyin Kozak ${ }^{D_{1}}$, Hasan Hüseyin Kır ${ }^{i}{ }_{1}$, Ahmet Buğrul ${ }^{D}{ }_{1}$, Osman Koç ${ }_{2}$ \\ 1 Necmettin Erbakan Üniversitesi Meram Tıp Fakültesi Nöroloji Kliniği, Konya, Türkiye \\ 2 Necmettin Erbakan Üniversitesi Meram Tıp Fakültesi Radyoloji Kliniği, Konya, Türkiye
}

Geliş: 07.07.2020; Revizyon: 12.01.2021; Kabul Tarihi: 18.01.2021

Öz

Amaç: İnternal karotis arter gibi supraaortik büyük arter tıkanıklarında mortalite ve kalıcı özürlülük oranı daha yüksektir. Dolayısıyla karotis arter darlıklarının erken tespiti klinik açıdan önem arzetmektedir. Aterom plağının distale olan akımı kısıtlayacak derecede stenoza neden olması sonucunda karşımıza çıkan "sınır zonu infarktı" ise karotis arter darlıklarında normalden çok daha sık olarak karşımıza çıkarak karotis arter darlığı açısından uyarıcı olabilmektedir. Bu çalışmada, kraniyal görüntülemelerinde sınır zonu infarktı izlenen ve etiyolojisinde karotis arter darlığı saptanarak karotis arter stentleme yapılan olgular incelenmiștir.

Yöntemler: Ocak 2017-Temmuz 2019 tarihleri arasında serebrovasküler hastalık tanısı ile takip edilmiş ve karotis arter stentleme yapılmış 120 olgu retrospektif olarak incelenmiş sınır zonu infarktı saptanan 31 olgu çalışmaya dahil edilmiştir.

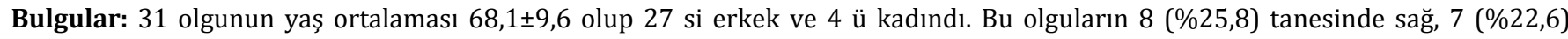
tanesinde sol, $16(\% 51,6)$ tanesinde bilateral karotis arter darlığı mevcuttu. En yüksek oranda eşlik eden komorbiditeler hipertansiyon 28 (\%90,3), hiperlipidemi 22 (\%71) ve koroner arter hastalığı 18(\%58,1) idi. Olguların17 (\%54,8)'inde geçici iskemik atak, 24 $(\% 77,4)$ 'ünde sigara içme öyküsü mevcuttu. 31 olgu radyolojik olarak değerlendirildiğinde $17(\% 54,8)$ tanesinde internal+eksternal, $(\% 16,1)$ tanesinde izole internal ve $9(\% 29)$ tanesinde izole eksternal sinır zonu infarktı saptandı. Olgulara iskemik inmeden ortalama $22,3 \pm 12,2$ gün sonra stentleme yapıldığı saptandı. Karotis arter stentleme sonrası 3 olguda minör inme saptandı. Minör inme sebebi ile bu olguların hastane yatış sürelerinin ortalama 6 gün uzadığı izlendi. Olguların pre-op ortalama modifiye rankin skorları $1.35 \pm 0.87$ iken işlemden 30 gün sonra $1.13 \pm 0.99$ idi. Tüm olguların birinci ay sonunda yaplan karotis arter doppler ultrasonografi incelemelerinde stent açıklığının tam olarak izlendiği ve restenoz saptanmadığı tespit edildi.

Sonuç: Sınır zonu infarktları karotis arter darlıkları açısından uyarıcı bir iskemik inme paternidir. Klinisyenlerin hastalığın tanınması ve tedavisinin yürütülmesi süreçlerinde etkin bir șekilde mücadele edebilmeleri için farkındalıkları arttırılmalıdır. Bu çalışma, sınır zonu infarktı ile gelen karotis arter darlıklı hasta gruplarında endovasküler stentleme yönteminin güvenli olduğuna ve erken dönemli sonuçlarının fonksiyonel sonlanımlar açısından olumlu sonuçlandığına işaret etmektedir.

Anahtar kelimeler: Karotis Arter Darlı̆̆ı; Sınır Zonu İnfarktı; Karotis Arter Stentleme

\section{DOI: 10.5798/dicletip.887668}

Correspondence / Yazışma Adresi: Hasan Hüseyin Kozak, Necmettin Erbakan Üniversitesi Meram Tıp Fakültesi Nöroloji Kliniği, Konya, Türkiye e-mail: hhkozak@gmail.com 


\title{
Clinical and Radıological Features of Patıents With Carotid Artery Stenosıs and Watershed Infarction and Early Outcomes of Carotid Artery Stenting
}

\begin{abstract}
Objective: Mortality and permanent disability rates are higher in supraaortic large artery occlusions such as the internal carotid artery. Therefore, early detection of carotid artery stenosis is clinically important. As a result of the atheroma plaque causing stenosis to a degree that restricts the flow to the distal, "border zone infarction" is more common than normal in carotid artery stenosis and can be a warning for carotid artery stenosis. In this study, patients who had border zone infarction and carotid artery stenting due to carotid artery stenosis were evaluated.
\end{abstract}

Methods: Between January 2017 and July 2019, 120 patients who were followed up with a diagnosis of cerebrovascular disease and carotid artery stenting were reviewed retrospectively. 31 cases with border zone infarction were included in the study

Results: The mean age of 31 cases (27 male, 4 female) was $68,1 \pm 9,6.8$ (25.8\%) of these cases had right, 7 (22.6\%) of them had left, and $16(51.6 \%)$ had bilateral carotid artery stenosis. The most seen comorbid disease were hypertension 28 (90.3\%), hyperlipidemia $22(71 \%)$ and coronary artery disease 18 (58.1\%). There was a transient ischemic attack in 17 (54.8\%) cases, and smoking in 24 $(77.4 \%)$ cases. When 31 cases were evaluated radiologically, 17 (54.8\%) internal + external, $5(16.1 \%)$ isolated internal and $9(29 \%)$ isolated external border zone infarcts were detected. It was determined that stenting was performed on average $22.3 \pm 12.2$ days after ischemic stroke.Minor stroke was detected in 3 cases after carotid artery stenting. Due to minor stroke, the hospitalization time of these cases was observed to increase 6 days on average. The pre-op mean mRS of the cases was $1.35 \pm 0.87$, while it was $1.13 \pm 0.99$ 30 days after the procedure. In the carotid artery doppler ultrasonography examinations performed at the end of the first month of all cases, it was determined that the stent patency was fully monitored and no restenosis was detected.

Conclusions: Border zone infarcts are a stimulating ischemic stroke pattern for carotid artery stenosis. Awareness of clinicians should be increased so that they can effectively fight the disease recognition and treatment processes. This study indicates that the endovascular stenting method is safe in patients with carotid artery stenosis that comes with border zone infarction, and that early results result positively in terms of functional outcomes.

Keyword: Carotid Artery Stenosis; Border Zone İnfarct; Carotid Artery Stenting.

\section{GíRiş}

İnmeye bağlı morbidite ve mortalite önemli bir sağlık sorunudur. İnternal karotis arter (İKA) gibi supraaortik büyük arter tıkanıklarında mortalite ve kalıcı özürlülük oranı daha yüksek görülmektedir. Tüm akut iskemik inmelerin yaklaşık \%30'unda neden İKA tıkanıklıklarıdır. IKA darlık sıklığı 6 . dekatta $\% 0,5$ iken, 80 yaşın üzerinde $\% 10$ 'a kadar ulaşmaktadır ${ }^{1,2}$.

Karotis arter darlığının en sık sebebi aterosklerozdur. Aterosklerotik süreç sonrası karotis arterlerde darlıklar oluşmaktadır ${ }^{3}$. Büyük arter aterosklerotik stenozu iki şekilde inmeye neden olmaktadır. Bunlardan sık görüleni proksimalde yer alan aterosklerotik plağın akut koroner olaylardakine benzer şekilde stabilizasyonunun bozulması, takiben tromboze olması ve daha sonra bu lezyondan kopan parçaların distal damarları tıkamasıdır. "Arterden artere embolizm" olarak tanımlanan bu klinik durum genellikle kortikal sendromlar ve territoryal infarktlar ile prezente olur ${ }^{4,5}$. Diğeri ise aterom plağının distale olan akımı kısitlayacak derecede stenoza neden olması sonucunda "sınır zonu infarktı" olarak karşımıza çıkar. Bu sınır zonu infarktlarının oluştuğu alanlar iki komşu serebral arter tarafından sulanan alanların arasında kalan bölgelerdir. Bu alanlarda kollateral dolaşımın yetersizliği nedeni ile bu bölgeler iskemi ya da infarkta daha açık hale gelirler. Sınır zonu infarktları eksternal ve internal olarak sinıflandırılmaktadır. Eksternal sinır zonu infarktları anterior serebral arterler (ASA), orta serebral arterler (OSA) ve posterior serebral arterlerin (PSA) beslediği bölgeler arasında meydana gelmektedir. İnternal sinır zonu infartkları ise derin beyaz cevherde perforan lentikülostriat arterler ile derin penetran OSA dalları arasında ya da ASA ve OSA'nın beyaz cevherde verdikleri derin dallar arasındadır 5 . 
Literatürde asemptomatik karotis arter darlığı olan olguların 5 yıllık optimal medikal tedavi ile takiplerinde ipsilateral inme veya ölüm oranı $\% 10,9$ olarak bulunmuştur ${ }^{6}$. Fakat semptomatik karotis arter darlığı olan olgularda ise 2 yıl içinde ölüm veya inme \%26 olarak oldukça yüksek bulunmuştur ${ }^{7,8}$. Özellikle çoklu risk faktörlerine sahip ve ileri dereceli stenozu olan olgu grupları sekonder inme açısından daha riskli grupta kabul edilmektedirler. $\mathrm{Bu}$ nedenle ileri dereceli stenozun tedavisi kritik bir öneme sahiptir. 65 yaş ve üstü olmak, erkek olmak, koroner arter hastalığı ve hipertansiyon öyküsü olmak önemli klinik risk faktörlerinin başında gelmektedir9 ${ }^{9}$.

Kuzey Amerika Semptomatik Karotis Endarterektomi Çalışması (NASCET), Avrupa Karotis Cerrahisi Çalışması (ECST) çalışmaları ve son yıllarda yapılan birçok klinik çalışma, semptomatik karotis darlığı olan hastalarda karotis arter stentlemesi (KAS) veya karotis endarterektomi (KEA) kullanılarak karotis revaskülarizasyonunun yararlarını göstermiştir ${ }^{10-15}$. Günümüzde özellikle de yeni geliştirilen cihaz ve yöntemlerle KAS, standart KEA'ya alternatif olarak kabul edilebilir bir tedavi yöntemi haline gelmeye başlamıştır ${ }^{16,17}$. Sinır zonu infarktlarında endarterektomi veya stentleme ile arteryel revaskülarizasyonun, inmenin erken ve geç dönemlerinde inme kliniğine olumlu katkıları olduğu düşünülmektedir 5 .

Bu çalışmada, akut inme bulguları ile başvuran, kraniyal radyolojik görüntülemelerinde sınır zonu infarktı saptanan ve etiyolojisinde karotis arter darlığı saptanarak karotis arter stentleme yapılan olgular klinik ve radyolojik özellikleri ile stentlemeye ait erken dönem sonuçları açısından incelenmiştir.

\section{YÖNTEMLER}

\section{Veri toplama}

Necmettin Erbakan Üniversitesi Meram Tip Fakültesi Hastanesinde Ocak 2017- Temmuz 2019 tarihleri arasinda v2.20.14 20200406 versiyonu numaralı ENLİL sistemi üzerinden ICD I67 (serebrovasküler hastalıklar, diğer), I63 (serebral enfarktüs), G46 (serebrovasküler hastalıklarda beynin vasküler sendromları) kodlarından biri girilerek takip edilmiş ve karotis arter stentleme yapılmış 120 olgu retrospektif olarak tarandı. Bu olguların akut iskemik inmelerine ait manyetik rezonans (MR) görüntüleri incelenerek içlerinden sinır zonu infarktı (șekil-1) saptanan 31 olgu çalıșmaya dahil edildi. Çalışmaya dahil edilen 31 olgunun tamamı nörolojik bulguların eşlik ettiği bir iskemik atak geçirmiş, NASCET kriterlerine göre değerlendirilmiş ve dijital substraksiyon anjiyografide \%50'den fazla ICA stenozu saptanmış olan olgulardı. Tüm bu olguların verileri ENLİL dökümantasyonu üzerinden incelendi. Yaș, cinsiyet, hipertansiyon (HT), diabetes mellitus (DM), hiperlipidemi (HL), koroner arter hastalığı (KAH), konjestif kalp yetmezliği (KKY), atriyal fibrilasyon (AF), koroner arter bypas greft operasyonu (CABGO), kronik böbrek yetmezliği (KBY), antiagregan veya antikoagülan kullanımı, SVO ve/veya TIA öyküsü, soygeçmişte SVO öyküsü, karotis arter hastalığının klinik özellikleri ve işlem sonrası stent açıklığının kontrol edildiği doppler USG ölçümleri dâhil klinik takipler olgu dosyalarından ve hastane kayıtlarından topland. Eksik bilgiler; olgular telefonla aranarak tamamlandı. Araştırma Helsinki Deklarasyonu'na uygun olarak gerçekleştirildi. Necmettin Erbakan Üniversitesi Meram Tip Fakültesi yerel etik komitesi tarafından 22.05.2020 tarihinde 2020/2513 sayılı karar ile onaylandi. 


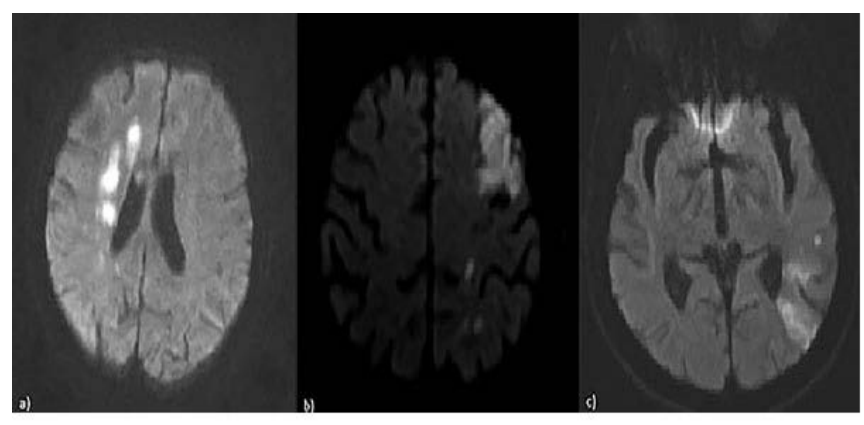

Şekil 1: a) internal sınır zonu infarktı b) anterior eksternal sinır zonu infarktı c) posterior eksternal sınır zonu infarktı

\section{İstatistik}

İstatistiksel analiz için SPSS 25.0 (Statistical Package for the Social Sciences) programı kullanıldı. Verilerin tanımlayıcı istatistiklerinde ortalama, ortanca, en düşük frekans, en yüksek frekans ve standart sapma (SS) kullanıldı. Değişkenlerin normallik dağılımı Kolmogorov Simirnov test ile ölçüldü. Nicel bağımsız verilerin analizinde ANOVA (normal dağılım için) ve Kruskal Wallis test (anormal dağılım için) kullanıldı. Nitel bağımsız verilerin analizinde ki-kare test kullanıldı. Grupların karşılaştırılmasında $p$ değeri 0.05 altındaki değerler anlamlı olarak kabul edildi.

\section{SONUÇLAR}

Çalışmaya 27 erkek(\%87,1), 4 kadın(\%12,9) olmak üzere toplam 31 hasta dahil edildi. 7 hastaya (6 erkek,1 kadın) bilateral karotis stentlemesi yapıldığı saptandı. Yapılan toplam 38 stentlemenin 33'ü erkeklere $(\% 86,8)$, 5'i kadınlara $(\% 13,2)$ yapılmıştı. Bütün olguların

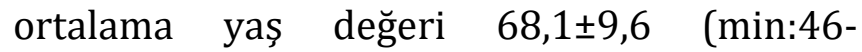
maks:86), erkeklerin 68,44 $\pm 10,33$ (min:46maks:86) ve kadınların 66,5 $\pm 1,73$ (min:65maks:69) idi.

Olgular komorbidite ve risk faktörleri açısından değerlendirildiği zaman $15(\% 48,4)$ diabetes mellitus (DM), $28(\% 90,3)$ hipertansiyon (HT), 22 (\%71) hiperlipidemi (HL), 18 (\%58,1) koroner arter hastalığı (KAH), $1(\% 3,2)$ kronik böbrek yetmezliği (KBY), 2 (\%6,5) konjestif kalp yetmezliği (KKY), $2 \quad(\% 6,5)$ atriyal fibrilasyonlu (AF) olgu mevcuttu. 5 $(\% 16,1)$ 'inde koroner bypass cerrahisi (KBC), $17(\% 54,8)$ 'inde geçici iskemik atak (GIA) öyküsü ve $24(\% 77,4)$ 'ünde sigara içme öyküsü saptandı. $11(\% 35,5)$ olgunun soy geçmişinde geçirilmiş SVO öyküsü bulunuyordu. Olguların darlık olan tarafı ile komorbidite veya sosyodemografik özellikleri arasında anlamlı bir istatiksel ilişki saptanmadı (Tablo I).

Olgular inme öncesi antiagregan ve antikoagülan kullanımları açısından incelendiğinde20 $(\% 64,5)$ olgunun antiagregan, $1(\% 3,2)$ olgunun antikoagülan kullanımı olduğu ve $10(\% 32,3)$ olgunun geçirdikleri iskemik inme öncesi antiagregan veya antikoagülan kullanımının olmadığı saptandı.

Olguların 8 tanesinde sağ, 7 tanesinde sol ve 16 tanesinde her iki karotiste \%50'den fazla darlık saptandı. Karotis darlıklarının $6(\% 12,8)$ tanesi \%50-69, $10(\% 21,3)$ tanesi \%70-79, $6(\% 12,8)$ tanesi \%80-89, 21 (\%44,7) tanesi \%90-99 ve4 $(\% 8,5)$ tanesi \%100 derecesindeydi. Karotis darlıklarının sağ, sol ve bilateral olmak üzere taraflarına göre dağılımı sırasıyla \%50-69 arası (n:0,n:0,n:6), \%70-79 arası (n:1,n:3,n:6), \%80$89 \quad \operatorname{arasi}(n: 1, n: 1, n: 4), \quad \% 90-99$ arası (n:6,n:3,n:12), \%100 olan (n:0,n:0,n:4) şeklindeydi. \%100 darlık oranı sadece bilateral darlığı olan olgularda gözlendi. Yani; oklüde olan tüm karotis arterlerin karşı tarafında da \%50'den fazla darlık mevcuttu. Stentleme öncesi değerlendirmeye alınan toplam 47 karotisin ortalama darlık oranı \%80,21 olarak saptandl. 
Tablo I: Olguların klinik ve radyolojik özellikleri

\begin{tabular}{|c|c|c|c|c|c|}
\hline & $\begin{array}{c}\text { Sağ İKA Darlık } \\
\text { n:8 }\end{array}$ & $\begin{array}{c}\text { Sol İKA Darlık } \\
\text { n:7 }\end{array}$ & $\begin{array}{c}\text { Bilateral İKA } \\
\text { Darlık } \\
\text { n:16 }\end{array}$ & $\mathbf{p}$ & $\begin{array}{c}\text { Toplam } \\
\text { n:31 }\end{array}$ \\
\hline \multicolumn{6}{|l|}{ Sosyodemografik özellikler } \\
\hline Yaş (ortalama $\pm S S$ ) & $66,1 \pm 8,5$ & $67,8 \pm 10,7$ & $69.3 \pm 10,1$ & 0.748 & $68,1 \pm 9,6$ \\
\hline Cinsiyet, Erkek n(\%) & $7(22,6)$ & $6(19,4)$ & $14(43,8)$ & 0.992 & $27(87,1)$ \\
\hline Cinsiyet, Kadın n(\%) & $1(3,2)$ & $1(3,2)$ & $2(6,5)$ & 0.992 & $4(12,9)$ \\
\hline \multicolumn{6}{|l|}{ Özgeçmiş } \\
\hline HT n $(\%)$ & $6(19,4)$ & $7(22,6)$ & $15(48,4)$ & 0.211 & $28(90,3)$ \\
\hline HL n(\%) & $6(19,4)$ & $4(12,9)$ & $12(38,7)$ & 0,657 & $22(71)$ \\
\hline $\mathrm{DM} n(\%)$ & $3(9,7)$ & $4(12,9)$ & $8(25,8)$ & 0,737 & $15(48,4)$ \\
\hline KAH n(\%) & $3(9,7)$ & $4(12,9)$ & $11(35,5)$ & 0,343 & $18(58,1)$ \\
\hline KKY n(\%) & $0(0)$ & $0(0)$ & $2(6,5)$ & 0,367 & $2(6,5)$ \\
\hline KBY n(\%) & $0(0)$ & $0(0)$ & $1(3,1)$ & 0,616 & $1(3,2)$ \\
\hline $\mathrm{AF} n(\%)$ & $2(6,5)$ & $0(0)$ & $0(0)$ & 0,046 & $2(6,5)$ \\
\hline Koroner Bypass n(\%) & $2(6,5)$ & $0(0)$ & $3(9,7)$ & 0,388 & $5(16,1)$ \\
\hline Antiagregan $\mathrm{n}(\%)$ & $2(6,5)$ & $5(16,1)$ & $13(41,9)$ & 0,023 & $20(64,5)$ \\
\hline Antikoagülan $\mathrm{n}(\%)$ & $1(3,2)$ & $0(0)$ & $0(0)$ & 0,226 & $1(3,2)$ \\
\hline GİA n(\%) & $4(12,9)$ & $3(9,7)$ & $10(32,3)$ & 0,650 & $17(54,8)$ \\
\hline Ailede SVOn(\%) & $1(3,2)$ & $3(9,7)$ & $7(22,6)$ & 0,288 & $11(35,5)$ \\
\hline Sigara $n(\%)$ & $5(16,1)$ & $6(19,4)$ & $13(41,9)$ & 0,490 & $24(77,4)$ \\
\hline Karotis Darlık Oranları & $\begin{array}{c}\text { Sağ İKA } \\
\text { n:8 }\end{array}$ & $\begin{array}{c}\text { Sol İKA } \\
\text { n:7 }\end{array}$ & $\begin{array}{r}\text { Bilat } \\
\text { n:1 } \\
\text { sağ n:16 sol } \mathrm{n}: 1\end{array}$ & & $\begin{array}{c}\text { Toplam } \\
\text { n:47 }\end{array}$ \\
\hline Darlık oranı \%50-69 n(\%) & $0(0)$ & $0(0)$ & $4(8,5)$ & $2(4,3)$ & $6(12,8)$ \\
\hline Darlık oranı \%70-79 n(\%) & $1(2,1)$ & $3(6,4)$ & $3(6,4)$ & $3(6,4)$ & $10(21,3)$ \\
\hline Darlık oranı \%80-89 n(\%) & $1(2,1)$ & $1(2,1)$ & $2(4,3)$ & $2(4,3)$ & $6(12,8)$ \\
\hline Darlık oranı \%90-99 n(\%) & $6(12,8)$ & $3(6,4)$ & $4(8,5)$ & $8(17,0)$ & $21(44,7)$ \\
\hline Darlık oranı \%100 n(\%) & $0(0)$ & $0(0)$ & $3(6,4)$ & $1(2,1)$ & $4(8,5)$ \\
\hline \multicolumn{6}{|l|}{ Darlık ortalaması min-maks } \\
\hline Radyolojik özellikler & $\begin{array}{c}\text { Sağ İKA Darlık } \\
\text { n:8 }\end{array}$ & $\begin{array}{c}\text { Sol İKA Darlık } \\
\text { n:7 }\end{array}$ & $\begin{array}{c}\text { Bilateral İKA } \\
\text { Darlık } \\
\text { n:16 }\end{array}$ & $\mathbf{p}$ & $\begin{array}{c}\text { Toplam } \\
\text { n:31 }\end{array}$ \\
\hline Izole internal & $1(3,2)$ & $0(0)$ & $4(12,9)$ & 0,308 & $5(16,1)$ \\
\hline Internal+eksternal SZİ n(\%) & $4(12,9)$ & $3(9.7)$ & $10(32,3)$ & 0.650 & $17(54,8)$ \\
\hline Izole eksternal SZI n(\%) & $3(9.7)$ & $4(12,9)$ & $2(6,5)$ & 0.063 & $9(29)$ \\
\hline İnternal SZİ n(\%) & $5(16,1)$ & $3(9,7)$ & $14(45,2)$ & 0.079 & $22(71)$ \\
\hline
\end{tabular}




\begin{tabular}{|l|c|c|c|c|c|}
\hline Eksternal SZİ n(\%) & $7(22,6)$ & $7(22,6)$ & $12(38,7)$ & 0.309 & $26(83,9)$ \\
\hline Anterior SZİ n(\%) & $6(19,4)$ & $5(16,1)$ & $9(29)$ & 0,604 & $20(64,5)$ \\
\hline Posterior SZİ n(\%) & $3(9,7)$ & $6(19,4)$ & $10(32,3)$ & 0.159 & $19(61,3)$ \\
\hline A+P SZİ n(\%) & $2(6,5)$ & $4(12,9)$ & $7(22,6)$ & 0.443 & $13(41,9)$ \\
\hline İnme-stent süresi & $20,8 \pm 8,9$ & $23,2 \pm 13,2$ & $22.6 \pm 13,8$ & 0.924 & $22,3 \pm 12,2$ \\
\hline Fonksiyonel sonlanım & & & & 0.115 \\
\hline mRS giriş & $1,50 \pm 1,06$ & $1.86 \pm 0.69$ & $1.06 \pm 0.77$ & $1.35 \pm 0.87$ \\
\hline mRS 30.gün & $1.25 \pm 1.28$ & $1.57 \pm 0.78$ & $0.88 \pm 0.88$ & 0.286 & $1.13 \pm 0.99$ \\
\hline
\end{tabular}

AF: Atriyal fibrilasyon, DM: Diyabetes Mellitus, GİA: Geçici iskemik atak HT: Hipertansiyon, IKA: Internal Karotis Arter, KAH: Koroner arter hastalı̆̆, KBY: Kronik böbrek yetmezliği, KKY: Konjestif kalp yetmezliği, mRS:Modifiye Rankin Skoru SS: Standart sapma, SVO: Serebrovasküler olay

Çalışmamıza alınan 31 hastanın manyetik rezonans (MR) görüntülemeleri incelendiğinde $17(\% 54,8)$ olguda internal ve eksternal sinır zonu infarkt birlikteliği mevcuttu. $5(\% 16,1)$ inde izole internal $9(\% 32,3)$ unda ise izole eksternal sınır zonu infarktı olduğu gözlendi. Toplam $26(\% 83,4)$ olguda saptanan eksternal sinir zonu infarktlarının alt tipleri incelendiğinde $13(\% 41,9)$ olguda anterior ve posterior sinır zonu infarktları birliktelik arzetmekteydi. $7(\% 22,6)$ olguda izole anterior $6(19,4)$ olguda ise izole posterior kortikal sinır zonu infarktı saptandı.

8 i sağ ve 7 si sol olmak üzere başvurusunda tek taraflı karotis darlığına sahip olan 15 olgunun akut inme ile stentleme işlemi arasında geçen süreleri incelendiğinde sağ karotis darlığı olan olguların inme ile işlem arası ortalama süresi $20,8 \pm 8,9$ gün iken sol karotis darlı̆̆ olan olguların ise $23.2 \pm 13.2$ gün idi.

Bilateral karotis darlığı olan olguların akut inme ile stentleme işlemi arasında geçen süre 22.6 \pm 13 . 8 gündü. Bilateral karotis darlığı olan 16 olgunun 10 una tek taraflı, 6 sina çift taraflı stentleme yapıldığg saptandı. Çift taraflı darlığı olmasına rağmen tek taraflı stentleme yapılan 10 olgu incelendiğinde 5'inin karşı karotisinin oklude olduğu görüldü. Diğer 5 olguda ise karşı taraf karotisinin asemptomatik olması ve \%50 oranında dar olması nedeniyle stentleme endikasyonu saptanmadığı görüldü.
Bilateral darlık tespit edilerek her iki karotise de stentleme yapılan 6 hasta incelendiğinde 2 hastanın her iki karotis stentlemesinin aynı seansta yapıldığı görüldü. Bu 2 olgudan birinin her iki karotisinde $\% 90$ ve diğerinin semptomatik tarafın $\% 90$ asemptomatik tarafın \%80 olmak üzere yüksek dereceli darlıklara sahip oldukları gözlendi. Her iki olgunun da stentleme işleminin inme sonrası ilk 10 gün içinde yapıldığı gözlendi. Diğer 4 olgu incelendiğinde ise birinci ve ikinci stentleme arasında yaklaşık 6 hafta olan 2 olgu mevcuttu. $\mathrm{Bu}$ olguların her ikisinin de semptomatik karotislerinin \%90 diğer karotislerinin ise \%70 oranında dar olduğu gözlendi. İlk olgunun birinci stentlemesinin akut inmeden 16 gün sonra ikinci stentlemesinin ise ilkinden 37 gün sonra, diğer olgunun ise birinci stentlemesinin akut inmeden 35 gün sonra ikinci stentlemesinin de ilkinden 45 gün sonra yapıldığı saptandı. Çift taraflı karotis darlığı tespit edilerek çift taraflı stentleme yapılan son 2 olgu incelendiğinde ilkinin inme sonrası 55. günde semptomatik olan $\% 90$ sol karotisine stentleme yapıldığı ve aynı dönemde tespit edilen \%80 sağ karotis darlığına da yakın bir tarihte stentleme önerildiği saptandı. Ancak hastanın kontrol muayenesine geç başvurduğu, yapılan kontrol vasküler görüntülemelerde de sağ karotis darlığının $\% 90$ a ulaştığ saptanılarak ilk stentlemeden 240 gün sonra karşı taraf stentlemesinin yapıldığı gözlendi. 
Diğer hastanın ise inme sonrası 18. günde sağ karotisine \%70 darlık nedeniyle stentleme yapıldığı, aynı görüntülemede sol karotis darlığının \%50 darlık oranına sahip olduğu, klinik takiplerinde ve tekrarlanan vasküler görüntülemelerinde sol karotis darlı̆̆ının $\% 80$ e ulaşmasıyla 445 gün sonra stentleme yapıldığ saptandl.

Akut inme sonrası tek taraflı karotis arter darlığı tespit edilerek stentleme yapılan, sonrasında klinik takiplerinde asemtomatik taraftaki karotisinde de darlık tespit edilmesiyle stentleme işlemi yapılmış 1 olgu olduğu saptandı. Olgunun verileri incelendiğinde hastanın sağ karotisine iskemik inmenin 24. gününde $\% 90$ darlık nedeniyle stentleme yapıldığı, o dönem karşı karotisinde $\% 50$ yi bulan bir darlık olmadığı ve tekrarlanan vasküler görüntülemelerinde sol karotis darlığının \%70 e ulaştığı saptanarak 496 gün sonra stentleme yapıldığı gözlendi.

31 olgudan 3 ünde yapılan stentleme işlemi sonrası minör inme geliştiği ve hastane yatış süresinin ortalama 6 gün uzadığı saptandı. Bu hastalardan birinin modifiye Rankin Skalası(mRS) skoru 1 puan artarken (mRS skoru 1 iken 2 oldu) diğer ikisinin mRS skorlarında değişme olmadığı saptandı. Sonrasında komplikasyon gelişmeyen 28 olgunun fonksiyonel sonlanımlarını değerlendirmek amacıyla işlem öncesi mRS ve işlem sonrası 30. gün mRS'ları incelendiğinde 14 işlem sonrası olgularda mRS skorlarında bir puan düşme olduğu ve hepsinin inme sonrası ilk 30 gün içinde işlem yapılan olgular olduğu gözlendi. Diğer 14 olguda ise stent öncesi ile stent işlemi sonrası 30. gün mRS puanlarında değişiklik saptanmadı. Akciğer kanseri ile takip edilen bir olgunun postprosedüral işlemle ilişkili herhangi bir komplikasyon ve yeni bir iskemik inme olayı saptanmaması rağmen, solunumsal problemlerden dolayı taburcu olamadığı ve yatışının 56. gününde eksitus olduğu saptandı.
Tüm olguların giriş ve 30. gün mRS ortalamaları sırasiyla $1.35 \pm 0.87 \mathrm{ve} 1.13 \pm 0.99$, sağ karotis darlığ olanlarda $1,50 \pm 1,06$ ve $1.25 \pm 1.28$, sol karotis darlı̆̆ $1.57 \pm 0.78$, bilateral karotis darlık olanlarda $1.06 \pm 0.77$ ve $0.88 \pm 0.88$ idi.

Olgulara prosedüre uygun bir şekilde birinci ayın sonunda yapilan karotis arter doppler ultrasonografilerde restenoz veya stent ilişkili herhangi bir komplikasyon tespit edilmedi ve stent açıklıkları tam olarak saptandı.

\section{TARTIŞMA}

Karotis arter darlığ serebrovasküler olayların yaklaşı \%30'undan sorumlu tutulmaktadır ${ }^{1}$. Büyük arter aterosklerotik stenozları inmeye tromboembolik veya hipoperfuzyona bağlı olarak neden olmaktadir ${ }^{5}$. Birbirleriyle anastomuzu olmayan iki arter bileşkesindeki distal sulama alanlarındaki infarklara sınır zonu infarktı (SZI) denir ${ }^{12}$. İskemik inmelerin $\% 10^{\prime}$ luk dilimini SZİ oluşturmaktadır ${ }^{10}$. SZI tutulum yerlerine göre internal (subkortikal) ve eksternal (kortikal) olmak üzere ikiye ayrılmaktadır. İnternal sınır zonu infarktları (ISi) daha çok karotis arter hattı boyunca olan darlıkların sebep olduğu hipoperfuzyon ile ilişkilendirilirken izole eksternal sınır zonu infarktları (ESI) ise daha çok mikroembolik olaylar ile ilişkilendirilmiştir. ESİ kortikal alanlardaki anterior serebral arter (ASA), orta serebral arter (OSA) ve posterior serebral arter (PSA) beslenme bölgelerinin arasında görülür ve genellikle kama veya ovoid görünümündedir. İSI ise lateral ventrikül hattı ve biraz üzerindeki beyaz cevherde OSA'nın derin ve yüzeyel dalları arasındaki bölgeler ile OSA ve ASA arasındaki yüzeyel dalların beslediği bölgelerde görülmektedir. Sentrum semiovalede görülen tespih benzeri infarklar ile hipoperfuzyon arasında yüksek ilişki kurulmuştur ${ }^{12}$. Tüm iskemik inmelerin \%10'unu sinır zonu infarktları oluştururken bu oran KAD'a bağlı 
inmelerde \%30'a çıkmaktadır. Bu çalışmada, verileri incelenen iskemik inme sonrası KAD'a bağlı stentleme yapılmış 120 olgunun 31 $(\% 25,8)$ inde literatüre benzer şekilde SZİ mevcuttu.

Birden fazla eşlik eden hastalığın bulunması multimorbidite olarak tanımlanmaktadır. Morbiditesi fazla olan olgular daha erken yașta semptomatik inme atakları geçirmektedir. Çoklu risk faktörleri olan olguların asemptomatik olsa bile inme riskinde artma bildirilmiștir ${ }^{18}$. 5 olgu haricindeki olguların tamamında birden fazla komorbidite olduğu gözlendi. HT $(\% 90,3)$ en sık görülen komorbiditeydi ve onu sırasıyla hiperlipidemi (\%71) ve $\mathrm{KAH}(\% 58,1)$ izliyordu. Büyük çoğunluğunda sigara içme öyküsü $(\% 77,4)$ vardı. Birçok çalışmada iskemik inme olgularında en çok görülen komorbidite incelediğimiz olgularda da olduğu gibi HT olarak saptanmıştır ${ }^{18,19}$.

KAD için medikal tedavi ve medikal tedaviye ek olarak revaskülarizasyon tedavisi yöntemlerinin uygulanması da önerilmektedir. $\% 50$ 'den fazla karotis darlığı olan olgulara tek başına medikal tedavi önerilmemektedir. Bu tip olgularda medikal tedavi ile birlikte uygulanacak revaskülarizasyon tedavileri tek başına medikal tedaviye üstün bulunmuştur ${ }^{20-}$ 22. Revaskülarizasyon amaçlı karotis arter endarterektomi(KAE) ve karotis arter stentleme(KAS) işlemleri uygulanmaktadır ${ }^{23}$. İnme sonrası revaskülarizasyon işleminin zamanı ve yöntemini karşılaştıran çalışmalarda ilk 2-14 gün arası dönemin; yapılan revaskülarizasyon işleminin tekrarlayan inme riskini en çok azalttığı dönem olduğu bildirilmiştir ${ }^{24}$. Sınır zonu infarktı ile başvuran hastalarda erken dönemde(<90gün) yapılan karotis stentlemenin geç dönemde( $>90$ gün) yapılan karotis stentlemelerine göre daha az sekonder inme ve daha iyi fonksiyonel iyileşme gösterdiği saptanmıştır ${ }^{26}$. Bilateral karotis stentlemenin de kademeli veya eş zamanlı yapılmasının güvenli olduğu çeşitli çalışmalarda gösterilmiștir ${ }^{27-30}$.

Çalıșmamızda değerlendirmeye alınan 31 olgunun akut inme sonrası stentleme zamanları incelendiğinde tamamına ilk 60 gün içinde stentleme işlemi uygulandığı saptandı. Bu 31 olgunun dağılımı ise inme sonrası ilk 14 gün 8, 14-30 gün arası 15 ve 30-60 günler arası 8 olgu şeklindeydi. İşlem sonrası komplikasyon gelişen 3 olgunun stentleme zamanı incelendiğinde 2 tanesinin 14-30 gün arası yapılan olgulardan, 1 tanesinin ise ilk stentlemesi komplikasyonsuz bir şekilde 18. günde yapılıp o dönem $\% 50$ olan darlığının 445 gün sonra $\% 80$ e ulaşmasıyla yapılan karşı taraf stentleme işlemi sonrası inme geçiren bir olgu olduğu gözlendi. İlk 14 gün KAS yapılan olgularda işlem ile ilgili komplikasyon gelişmediği saptandı. Karotis stentleme sonrası 30 günlük inme, miyokard infarktüsü(MI) ve ölüm sonlanım oranları CAVATAS çalışmasında $\% 10$, EVA-3S çalışmasında \%9,6, SPACE çalışmasında \%6,64, CREST çalışmasında $\% 5,2$, ACT-1 çalışmasında \%2,9 olarak bildirilmiştir 25 . İncelediğimiz olguların 30 günlük inme sonlanım oranı ise\%9,7 (n:3) idi. Tümünün minör iskemik inme olduğu ve bu 3 olgunun hastane yatış sürelerinin ortalama 6 gün uzadığı saptand.

Tüm olguların giriş ve 30 . gün mRS skor ortalamaları sirasiyla $1.35 \pm 0.87$ ve $1.13 \pm 0.99$, sağ karotis darlığ olanlarda $1,50 \pm 1,06$ ve $1.25 \pm 1.28$, sol karotis darlığ $1.86 \pm 0.69$ ve $1.57 \pm 0.78$, bilateral karotis darlık olanlarda $1.06 \pm 0.77$ ve $0.88 \pm 0.88$ idi. Benzer șekilde yapılan bir çalışmada tek taraflı stentleme yapılan olgularda giriş $1 ; 87 \pm 0,96$ ve 1 yıl sonra 1,64 $\pm 0,96$, bilateral stentleme yapilan olgularda ise giriş mRS 1,56 $\pm 1,01$ ve bir yll sonraki takibi $1,44 \pm 1,00 \mathrm{idi}^{26}$.

Karotis stentleme sonrası restenoz oranları 5 yıllık izlem yapılan CAVATAS çalışmasında \%16.6, 3 yıllık izlem yapılan SAPPHIRE ve EVA- 
3S çalışmalarında \%3 ve 3.3, 2 yıllık izlem yapılan CREST ve SPACE çalışmalarında \%6 ve 11.1 olarak bildirilmiştir ${ }^{27}$. İncelediğimiz olgulara ise stentleme işleminden 30 gün sonra stent patensi kontrolü amaciyla doppler USG yapıldığı, sonucunda restenoz gözlenmediği ve stent açıklıklarının tam olarak değerlendirildiği saptandl.

Her ne kadar çalışma verileri literatürle uyumlu saptanmış olsa da,çalışmanın geriye doğru tarama ile gerçekleştirilmesi, çalışmanın hem karotis darlıklı hem de sinır zonu infarktı saptanan hasta grubu gibi örneklem boyutunu küçülten sıkı bir dahil edilme kriteri taşıması nedeniyle gerekenden daha az sayıda bir hasta grubu ile yapılabilmesi, uzun dönemli verilere erişmede yaşanan zorluklar ve tek bir merkezin biriktirebildiği sonuçlar olması çalışmanın kısıtlılıklarıdır. Bununla birlikte bütün kısıtlılıklara rağmen sunulan verilerin yapılacak büyük analiz çalışmaları için önemli bir veri kaynağı haline geleceğini düşünmekteyiz.

\section{KARAR}

İnmeye bağlı morbidite ve mortalite önemli bir sağlık sorunudur. İKA gibi supraaortik büyük arter tıkanıklarında mortalite ve kalıcı özürlülük oranı daha yüksek görülmektedir. Dolayısıyla karotis arter darlıklarının erken tespiti klinik açıdan önem arzetmektedir. Aterom plağının distale olan akımı kısıtlayacak derecede stenoza neden olması sonucunda karşımıza çıkan "sınır zonu infarktı" karotis arter darlıklarında normalden çok daha sık olarak karşımıza çıkarak karotis arter darlığı açısından uyarıcı olabilmektedir. Dolayısıyla klinisyenlerin hastalığın tanınması ve tedavisinin yürütülmesi süreçlerinde etkin bir şekilde mücadele edebilmeleri için farkındalıkları arttırılmalıdır. KAD’lar açısından uyarıcı olma özellikleri nedeniyle sınır zonu infarktlarının hızlıca tanınabilmeleri, erken tespiti ciddi önem taşıyan karotis arter darlıklı hastaların hem tedavilerinde hem de takiplerinde önemli bir rol alabilir. Ayrıca bu çalışma, sunduğu veriler itibarıyla sınır zonu infarktı ile gelen karotis arter darlıklı hasta gruplarında tedavi yönetiminde endovasküler stentleme yönteminin güvenli olduğuna ve erken dönemli sonuçlarının fonksiyonel sonlanımlar açısından da olumlu sonuçlandığına işaret etmektedir.

Etik Kurul Kararı: Araştırma Helsinki Deklarasyonu'na uygun olarak gerçekleştirildi. Necmettin Erbakan Üniversitesi Meram Tıp Fakültesi yerel etik komitesi tarafından 22.05.2020 tarihinde 2020/2513 sayılı karar ile onaylandı.

Çıkar Çatışması Beyanı: Yazarlar çıkar çatışması olmadığını bildirmişlerdir.

Finansal Destek: Bu çalışma her hangi bir fon tarafından desteklenmemiştir.

Declaration of Conflicting Interests: The authors declare that they have no conflict of interest.

Financial Disclosure: No financial support was received.

\section{KAYNAKÇA}

1. Phatouros CC, Higashida RT, Malek AM, et al. Carotid artery stent placement for atherosclerotic disease: rationale, technique, and current status. Radiology. 2000; 217: 26-41.

2. Kirsch EC, Khangure MS, van Schie GP, et al. Carotid arterial stent placement: results and follow-up in 53 patients. Radiology. 2001; 220: 737-44.

3. Ertaş F, Çevik MU, Aluçlu MU, et al. Karotis arter stentlemesi: İnvaziv bir üçüncü basamak merkez deneyiminin retrospektif değerlendirilmesi. Dicle Med J 2016; 43: 141-5.

4. Rennert RC, Wali AR, Steinberg JA, et al. Epidemiology, Natural History, and Clinical Presentation of Large Vessel Ischemic Stroke. Neurosurgery. 2019; 85(suppl_1): S4-s8.

5. Weill C, Suissa L, Darcourt J, Mahagne MH. The Pathophysiology of Watershed Infarction: A ThreeDimensional Time-of-Flight Magnetic Resonance Angiography Study. J Stroke Cerebrovasc Dis. 2017; 26: 1966-73.

6. Halliday A, Harrison M, Hayter E, et al. 10-year stroke prevention after successful carotid endarterectomy for 
asymptomatic stenosis (ACST-1): a multicentre randomised trial. The Lancet. 2010; 376(9746): 107484.

7. Brott TG, Halperin JL, Abbara S, et al. Guideline on the management of patients with extracranial carotid and vertebral artery disease. J Am Coll Cardiol. 2011; 57: 516-94.

8. Organisation EbtES, Members ATF, Tendera M, et al. ESC Guidelines on the diagnosis and treatment of peripheral artery diseases: document covering atherosclerotic disease of extracranial carotid and vertebral, mesenteric, renal, upper and lower extremity arteries The Task Force on the Diagnosis and Treatment of Peripheral Artery Diseases of the European Society of Cardiology (ESC). European heart journal. 2011; 32: 2851-906.

9. Wilson PW, Hoeg JM, D'Agostino RB, et al. Cumulative effects of high cholesterol levels, high blood pressure, and cigarette smoking on carotid stenosis. New England Journal of Medicine. 1997; 337: 516-22.

10. Torvik A. The pathogenesis of watershed infarcts in the brain. Stroke. 1984; 15: 221-3.

11. Moriwaki $\mathrm{H}$, Matsumoto $\mathrm{M}$, Hashikawa $\mathrm{K}$, et al. Hemodynamic aspect of cerebral watershed infarction: assessment of perfusion reserve using iodine-123lodoamphetamine SPECT. Journal of Nuclear Medicine. 1997; 38: 1556-62.

12. Momjian-Mayor I, Baron J-C. The pathophysiology of watershed infarction in internal carotid artery disease: review of cerebral perfusion studies. Stroke. 2005; 36: 567-77.

13. O'Brien M, Chandra A. Carotid revascularization: risks and benefits. Vasc Health Risk Manag. 2014; 10: 403-16.

14. Liu H, Chu J, Zhang L, et al. Clinical comparison of outcomes of early versus delayed carotid artery stenting for symptomatic cerebral watershed infarction due to stenosis of the proximal internal carotid artery. BioMed research international. 2016; 2016.

15. Zhang C, Wang Y, Zhao X, et al. Clinical, imaging features and outcome in internal carotid artery versus middle cerebral artery disease. PloS one. 2019; 14.
16. Villwock MR, Padalino DJ, Deshaies EM. Carotid artery stenosis with acute ischemic stroke: stenting versus angioplasty. Journal of vascular and interventional neurology. 2015; 8: 11.

17. Jones DW, Brott TG, Schermerhorn ML. Trials and frontiers in carotid endarterectomy and stenting. Stroke. 2018; 49: 1776-83.

18. Gallacher KI, Jani BD, Hanlon P, Nicholl BI, Mair FS. Multimorbidity in Stroke. Stroke. 2019; 50: 1919-26.

19. Mudra H, Staubach S, Hein-Rothweiler R, et al. Long-term outcomes of carotid artery stenting in clinical practice. Circulation: Cardiovascular Interventions. 2016; 9: e003940.

20. Collaborators* NASCET. Beneficial effect of carotid endarterectomy in symptomatic patients with highgrade carotid stenosis. New England Journal of Medicine. 1991; 325: 445-53.

21. Group ECSTC. Randomised trial of endarterectomy for recently symptomatic carotid stenosis: final results of the MRC European Carotid Surgery Trial (ECST). The Lancet. 1998; 351(9113): 1379-87.

22. Ederle J, Brown MM. The evidence for medicine versus surgery for carotid stenosis. European journal of radiology. 2006; 60: 3-7.

23. Meschia JF, Klaas JP, Brown RD, Jr., Brott TG. Evaluation and Management of Atherosclerotic Carotid Stenosis. Mayo Clin Proc. 2017; 92: 1144-57.

24. Rothwell P, Eliasziw M, Gutnikov S, et al. Endarterectomy for symptomatic carotid stenosis in relation to clinical subgroups and timing of surgery. The Lancet. 2004; 363(9413): 915-24.

25. Salem MM, Alturki AY, Fusco MR, et al. Carotid artery stenting vs. carotid endarterectomy in the management of carotid artery stenosis: Lessons learned from randomized controlled trials. Surg Neurol Int. 2018; 9: 85.

26. Liu B, Wei W, Wang Y, et al. Treatment strategy for bilateral severe carotid artery stenosis: one center's experience. World neurosurgery. 2015; 84: 820-5.

27. Lal BK, Beach KW, Roubin GS, et al. Restenosis after carotid artery stenting and endarterectomy: a secondary analysis of CREST, a randomised controlled trial. Lancet Neurol. 2012; 11: 755-63. 